\title{
CORROSION AND ELECTROCHEMICAL IMPEDANCE SPECTROSCOPY OF THIN TIAIN AND TICN PVD COATINGS FOR PROTECTION OF BALLAST WATER SCREEN FILTERS
}

\author{
R. Kalnina*, V. Priednieks, K. Lukins, A. Gasparjans, A. Rijkure \\ Latvian Maritime Academy, \\ 5b Flotes Str., Riga, LV-1016, LATVIA \\ *e-mail: renate_kalnina@inbox.Iv
}

The electrochemical impedance spectroscopy (EIS) and corrosion behaviour of physical vapour deposited (PVD) TiAlN and TiCN coatings of $50 \mu \mathrm{m}$ mesh shaped AISI 316 stainless steel were estimated under simulated marine conditions ( 3.5 wt. \% $\mathrm{NaCl}$ solution). The coatings were prepared by creating adhesive $\mathrm{Cr}-\mathrm{CrN}$ interlayer with the thickness of about $0.3 \mu \mathrm{m}$. The obtained thicknesses of produced coatings were measured to be in a range between 2 and $3.5 \mu \mathrm{m}$. The presence of protective coatings leads to corrosion potential $\left(E_{\text {corr }}\right)$ shifting to more positive values as compared to the bare stainless steel. This effect indicates higher protection efficiency of coated steel under marine conditions. The protective behaviour of produced coating leads to the decreased corrosion current density $\left(j_{\text {corr }}\right)$ by indicating up to 40 -fold higher polarization resistance as compared to resistance of the naturally formed oxide layer over the stainless steel. The Nyquist and Bode plots were obtained with the help of EIS measurements by applying alternating potential amplitude of $10 \mathrm{mV}$ on observed $E_{\text {corr }}$. The obtained plots were fitted by appropriate equivalent circuits to calculate pore resistance, charge transfer resistance and capacitance. The present study reveals that pore resistance was the highest in the case of TiCN coating $\left(R_{\text {pore }}=3.22 \mathrm{k} \Omega \cdot \mathrm{cm}^{2}\right)$. The increase in duration of the immersion up to $24 \mathrm{~h}$ leads to change in the capacitive behaviour of the coatings caused by the penetration of the aqueous solution into pore system of TiCN coating with low wettability and surface passivation of reactive TiAlN coating. The presence of defects was confirmed by examining the obtained samples with the help of the scanning electron microscope.

Keywords: Coatings, corrosion, electrochemical impedance spectroscopy, marine conditions, protection, $P V D$. 
The mechanical degradation of stainless steel components causes the considerable attention during application under the industrial [1], electronics [2] marine, automotive and aerospace [3], [4] conditions for the certain period of exposure to mechanical, chemical, and electrochemical impacts. Ballast water stability and maneuverability are required to ensure the buoyancy of ships. The technological development provides the construction and use of larger sized modern cargo ships. It leads to the highest consumption and more frequent uptake and release of ballast water [5]. Ballast water tanker, pumping, and filtering systems typically experience the combination of above mentioned impacts and other types of severe wear causing factors [6].

It has been recently estimated that between 10 and 12 billion tons of ballast water are transported worldwide each year. The ballast water typically contains bacteria, plankton, viruses, small fish, crabs or jellyfish which are mostly invasive to ecosystems on the route of cruising ships. Studies have shown that around 7,000 marine and coastal species travel daily and frequently cross the world's oceans and seas in such a way. It results in irreversible ecological variations and economic losses [7].

The International Convention for the Control and Management of Ships' Ballast Water and Sediments (BWM 2004) was adopted by the International Maritime Organisation (IMO) in 2004 and subsequently entered into force on 8 September 2017 to perform action for the prevention of such a global environmental problem. The aims of BWM 2004 are to govern the process of ballast water exchange and reduce the risk of invasive aquatic species to influence the foreign ecosystems.
According to BWM 2004, the installations for treatment of ballast water and sediment are required and they should be completely implemented till 8 September 2024. In addition, it is important to underline that BWM 2004 does not define specific water treatment technologies. Eventually, shipowners must make a choice between existing technologies available on the market and innovative technologies recently introduced or currently under research and development. Innovative and sustainable technologies provide a clear advantage in meeting the demand for construction of new ships in accordance with the strictest environmental requirements [5]. The operation of currently applied ballast water management systems (BWMS) typically includes the combination of physical separation with centrifugal force and disinfection (e.g., electro-chlorination and ultraviolet - UV radiation) approaches.

Fixed or movable types of stainless steel-based ballast water screens or disks are typically applied during the pre-treatment stage of BWMS to efficiently remove suspended solids or organisms with sizes above $50 \mu \mathrm{m}$. Typical filters include automatic backwash (counter-flow) mechanisms for self-cleaning to ensure continuous operation. The main objective of such an approach is to reduce the degree of disinfection treatment and required contact time. It helps avoid the additional treatment caused by larger sized organisms that block the filter sieve mesh. It also leads to reduced concentration of sediment in ballast water. The presence of sediment particles reduces the efficiency of UV radiation and causes habitat for benthic organisms.

The backwash mode typically leads to the discharge of the suspended/filtered 
solids and wastewater from the filter in the same area where the ballast is taken. It should be noted that additional backwash water treatment is recommended before every discharging process [8].

It should be emphasised that all BWMS have been tested under aggressive terrestrial conditions with complex water conditions (different water parameters and large numbers of organisms) to demonstrate that the D-2 standard is met. Therefore, problems that cannot be foreseen are only brought to light in practice mainly due to clogging and corrosion of the screen filters.

The tendency of filters to clog relates primarily to filter design and small mesh sizes [9].

Filters with a nominal pore size in the range $\geq 10 \mu \mathrm{m}$ and $<50 \mu \mathrm{m}$ are typically applied to ballast water treatment. Simplistically, the ballast water discharge standard differentiates the target organisms in three size categories: $>50 \mu \mathrm{m}$ sized organisms (predominately zooplankton); 10-50 $\mu \mathrm{m}$ sized organisms (predominately algae) and larger sized bacteria. Most suppliers choose filtration with a cut-point at around $40 \mu \mathrm{m}$ resulting in an immediate and very efficient removal of zooplankton. The BWMS manufacturers offer $40 \mu \mathrm{m}$ ballast water self-cleaning filters made of stainless steel 304L, 316L for standard applications [10]. These facts typically cause the demand for the improved resistance of exposed components to reduce the expenditures for the required periodic shutdowns and repairs [11], [12].

The epoxy is one of the most popular currently applied steel elements protecting coating under marine conditions. The wear of such a coating leads to environmental pollution with highly stable microplastics [13]. The global demand for high-performance corrosion and wear resistant coatings and smart approaches stood nearly 14.61 billion
US\$ in 2018 and was projected to reach over 22.78 billion US\$ by 2027 [14]. The partial or complete replacement of microplastics or hazardous compounds generating coatings with more durable thin physical vapour deposited (PVD) coatings and development of innovative structures will evidently play a vital role in environmental protection. Wear, erosion, and corrosion are the most common forms of chemical and mechanical attack. The most common form of degradation is usually initiated at the surface of the materials under the harshest working environments.

Generally, the breakdown of the passive films, crevice corrosion, pitting, galvanic corrosion, inter-granular corrosion, selective leaching, erosion-corrosion, and chemical stress corrosion are more commonly investigated and reviewed types of corrosion in literature. As next to water, steel corroding chlorides are the most common chemicals found in nature. Therefore, chloride caused stress corrosion (cracking) requires more careful examination [15], [16].

It is important to minimise the concentration of growth defects in order to improve the tribological properties of PVD hard coatings [17], [18]. PVD coating technology had intensive progress last decade, and it was successfully adapted even for protection of fine powder coatings. Ceramic hollow particles have been coated with $\mathrm{Cu}$ metal (the thickness of 0.4-2.5 $\mu \mathrm{m}$ ) [19], [20]; Ti $(0.15-0.25 \mu \mathrm{m})$; and Ti-TiN (0.2$0.4 \mu \mathrm{m})$ [21]. The protection of $\mathrm{Mg}$-alloys with thin coatings is one of the most challenging objectives to enable the safe application of low density components under marine conditions [22], [23]. Current solutions still cannot meet automotive industry test requirements.

The metallic substrate has no direct contact with the corrosive environment in 
case of a typical coating-metal substrate system. However, the presence of voids, pinholes, droplets, poor adhesion, difference in chemical composition between the coating matrix and droplet lead to corrosion [24], [25]. These defects are considered the primary causes of failures in coating/metal systems.

It should be noted that macrodefects caused by inclusions in the dense coating do not always present a break-point in corrosion resistance [26]. Transition metal nitrides are widely applied due to high hardness, high electrically conductivity, and good corrosion resistance [27], [28]. Corrosion resistance of hard coatings, like TiAlN, $\mathrm{TiN}$, and TiCN, depends on microstructure defects. Such hard coatings typically exhibit trans-passive state under marine water conditions [28].

The mechanism of corrosion and material microstructure both play an important role in the corrosion process [29]. A coating/metal substrate system is examined in the present study to understand the effect of galvanic corrosion caused by the presence of defects in the coating. Electrochemical reaction is the prevalent corrosion mode. Electrochemical characterisation of the tested coatings is performed in the present study to investigate their corrosion behaviours in a simulated marine (corrosive) environment.

The corrosion behaviour of produced coated samples is studied and compared with the help of potentiodynamic polarization and the electrochemical impedance spectroscopy (EIS) methods. It should be noted that quantitative evaluation of the kinetic parameters for the observed corrosion mechanisms is a complicated process by employing the potentiodynamic polarization technique alone [30]CrN, TiAlN and multilayer TiAlN/CrN coatings, deposited on steel substrate using a multi-target reactive direct current magnetron sputtering process, were studied in $3.5 \% \mathrm{NaCl}$ solution by potentiodynamic polarization and electrochemical impedance spectroscopy (EIS). More detailed information about the electrochemical reaction at the electrode/ electrolyte interface can be interpreted with the help of appropriate equivalent circuit supported EIS measurement data. The use of EIS technique allows detecting the resistive and capacitive nature of the electrochemical interface, thus identifying the effect of micropores on the localized corrosion behaviour.

\section{THE OBJECT FOR RESEARCH AND DEVELOPMENT}

The high-quality stainless steel screen offered by most vendors has a relatively short lifespan. The failed stainless steel AISI 316L screen filter after 6-month long operation under real operational conditions was selected for preliminarily research and development activities at the Latvian Maritime Academy (LMA), as demonstrated in Fig. 1. The chemical and galvanic cor- rosion was observed as the main cause of the screen filter failure in addition to solid particles containing slurry that caused abrasive wear of the formed corrosion product layer (e.g., rust). Therefore, it was decided to apply hard coating over the stainless steel screen filter material to estimate the chemical and electrochemical corrosion resistance under simulated marine conditions. 


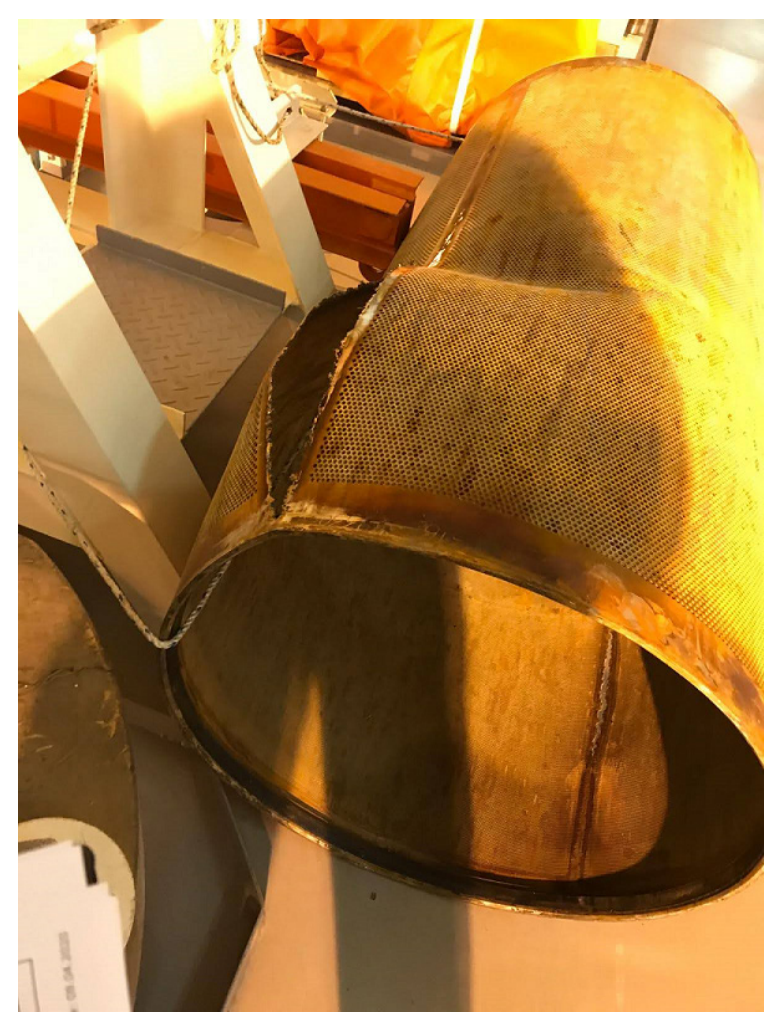

Fig. 1. Failed screen filter after 6-month service under real conditions.

\section{EXPERIMENTAL METHODS}

The $50 \mu \mathrm{m}$ mesh shaped flat substrate samples of stainless steel AISI 316 (EN 1.4401) with dimensions of $25 \times 15 \times 2 \mathrm{~mm}$ were polished with the help of the diamond polishing disc and SiC polishing pads down to $0.5 \mu \mathrm{m}$. The produced substrates were cleaned by immersion in the ultrasonic bath for $1 \mathrm{~h}$ with subsequent drying under vacuum and final sputter-cleaning in argon plasma with bias voltage $-850 \mathrm{~V}$ at $400{ }^{\circ} \mathrm{C}$ for $1 \mathrm{~h}$. The $\mathrm{Cr}-\mathrm{CrN}$ interlayer with the thickness of about $0.3 \mu \mathrm{m}$ was created to provide high adhesion strength between stainless steel substrate and the selected coatings. The interlayer coating and TiCN and TiAlN coatings (with a content of Al 0 and 55 at. $\%$, respectively) were deposited on substrate with the help of a modernised vacuum installation NNV-6,6-I1 [31], the operating principle of which is based on the method of PVD under a reactive nitrogen atmosphere. The deposition temperature for each coating was $500{ }^{\circ} \mathrm{C}$.

The obtained specimens are marked as follows: uncoated AISI $316(\mathrm{R})$, coated with TiCN (A) and TiAlN (B). A scanning electron microscope Hitachi TM3000 (Tabletop) equipped with energy-dispersive X-ray spectroscopy (EDS) was used to observe the surface morphology. The thickness of produced coatings was measured with the help of the kalotest method according to the method developed by $B A Q$ (Germany).

Potentiodynamic polarization and electrochemical impedance spectroscopy measurements were performed under simulated 
marine conditions $(3.5$ wt. $\% \mathrm{NaCl}$ solution) in the three-electrode (potentiostatic) mode in the presence of the saturated calomel reference electrode (SCE) and platinum $(\mathrm{Pt})$ counter electrode $(\mathrm{CE})$ with a working surface of $2 \mathrm{~cm}^{2}$. Protective silicone isolated specimens with an exposed surface area of about $1 \mathrm{~cm}^{2}$ were used as working electrodes (WE).

Potentiodynamic polarization measurements were performed using Autolab PGSTAT30 galvanostat/potentiostat system with General Purpose Electrochemical System GPES software. After the open circuit potential $\left(E_{O C P}\right)$ stabilization, lower potential limits of linear sweep voltammetry were set in a range between -0.7 and $0 \mathrm{~V}$ by selecting a scan rate of $5 \mathrm{mV} \cdot \mathrm{s}^{-1}$.

According to Faraday's law, the penetration rate is calculated by Eq. (1):

$C R=K_{1} \cdot \frac{i_{\text {corr }}}{\rho} \cdot E W_{\text {alloy }}$,

where $C R$ - the penetration rate (the thickness loss per unit of time), $\mathrm{mm} \cdot \mathrm{year}^{-1} ; K_{I}=$ $3.3 \cdot 10^{-3} \mathrm{~mm} \cdot$ year $^{-1}$ (only consistent valence groupings were used); $i_{\text {corr }}-$ corrosion current density $\left(\mu \mathrm{A} \cdot \mathrm{cm}^{-2}\right) ; \rho$ - alloy density, $\left(\mathrm{g} \cdot \mathrm{cm}^{-2}\right) ; E W_{\text {alloy }}-$ the alloy equivalent weight (dimensionless in this calculation) [32].
The protective efficiency $P_{i}(\%)$ of the coating was calculated as follows:

$P_{i}=\left[1-\frac{i_{\text {corr }}}{i_{\text {corr }}^{0}}\right] \times 100$,

where $i_{\text {corr }}$ and $i_{\text {corr }}^{0}$ indicate the corrosion current density of the coating and substrate, respectively.

The porosity $F(\%)$ of coating is calculated according to Eq. (3):

$F=\left[\frac{R_{p m}}{R_{p}} \times 10^{-\left.\right|^{\Delta E_{c o r r}} / \beta_{a}} \mid\right] \times 100$,

where $R_{p m}$ and $R_{p}$ are the polarization resistances of the substrate and coating-substrate systems (calculated by GPES according to Eq. (4)), respectively; $\Delta E_{c o r r}$ is the corrosion potential difference between the substrate and applied coating, and $\beta_{a}$ is the anodic Tafel constant of substrate [33].

$R_{p}\left(R_{p m}\right)=\left(\frac{\delta \Delta E}{\delta i}\right)_{i=0, d E / d t \rightarrow 0}$,

where a small potential scan $\Delta E(t)$ is defined with respect to the corrosion potential shown in Eq. (5) [32]:

$\Delta E=E-E_{\text {corr }}$.

\subsection{Electrochemical Impedance Spectroscopy}

Alternating current (AC) impedance for all specimens was derived using an AutoLab with potentiostat/galvanostat PGSTAT30 and Frequency Response Analyzer (FRA) module. A sinusoidal AC perturbation of $10 \mathrm{mV}$ amplitude was applied to the electrode at the observed $E_{\text {corr }}$ over the frequency range of $10 \mathrm{mHz}$ to $10 \mathrm{kHz}$ after short (approximately $10 \mathrm{~min}$ ) and long (approximately $24 \mathrm{~h}$ ) exposure time in a corrosive medium before testing by apply- ing the observed $E_{\text {corr }}$ (conditioning). NOVA 2 software was used for the analysis of the obtained plots and fitting to the selected equivalent circuits. Equivalent circuits were generated with the help of the EQUIVCRT software. It should be noted that specimens exposed for a long period were immersed in the fresh 3.5 wt. $\% \mathrm{NaCl}$ solution to avoid the effect of $\mathrm{NaCl}$ concentration changes caused by reactions and evaporation of the liquid phase. 


\section{RESULTS AND DISCUSSION}

The SEM images of the surface morphol-

coatings are shown in Fig. 2. ogy of the as-deposited TiCN and TiAlN

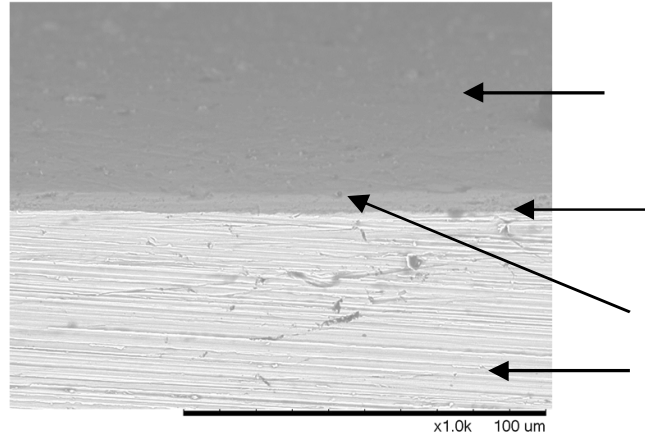

A $(\mathrm{TiCN})-$ cross-section

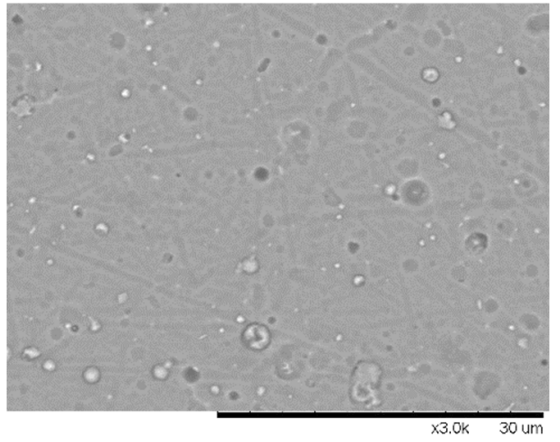

C (TiCN) - Surface

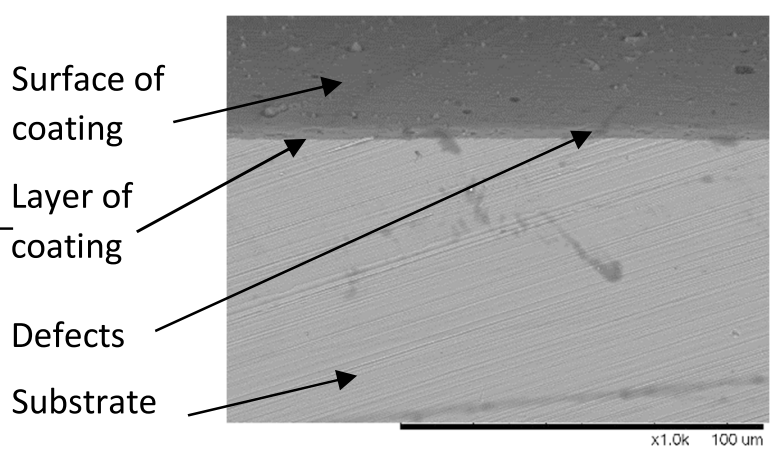

B (TiAlN) - cross-section

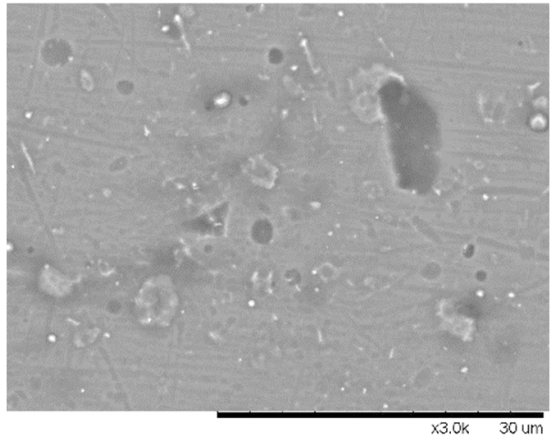

D (TiAlN) - Surface

Fig. 2. SEM coating and substrate cross-sections of TiCN (A) and TiAlN (B); and morphology of as-deposited coatings

$\operatorname{TiCN}(\mathrm{C})$ and TiAlN (D).

The Tafel plots obtained for steel substrate and coated specimens are shown in Fig. 3, and the obtained potentiodynamic polarization data from GPES are shown in Table 1. $E_{\text {corr }}$ of the steel substrate is about $-0.36 \mathrm{~V}$ and $i_{\text {corr }}$ is $1.79 \mu \mathrm{A} \cdot \mathrm{cm}^{-2}$. TiCN and TiAlN coatings show that $E_{\text {corr }}$ shifts towards the positive side $(-0.19$ and $-0.18 \mathrm{~V})$ with down to 20 -fold lower $i_{\text {corr }}$ as compared to the substrate. These results indicate better corrosion resistance for TiCN and TiAlN coatings over steel substrate, confirming that the transition metal nitrides are more inert to a chemical attack. 


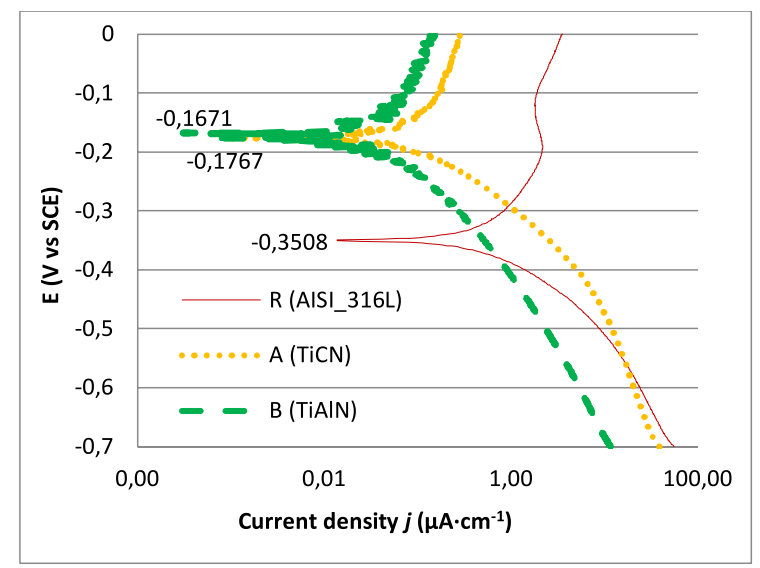

Fig. 3. Potentiodynamic polarization curves (Tafel plots) of as-received tested specimens.

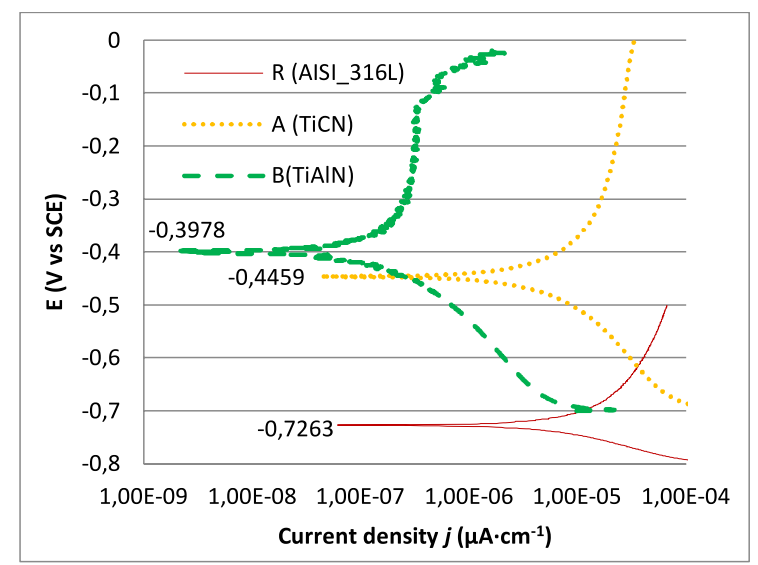

Fig. 4. Potentiodynamic polarization curves (Tafel plots) of as-received tested specimens after $24 \mathrm{~h}$ immersion.

Table 1. Potentiodynamic Polarization Data of Tested Specimens in 3.5 wt.\% NaCl Solution

\begin{tabular}{|l|c|c|c|c|c|}
\hline \multirow{2}{*}{} & $\boldsymbol{E}_{\text {corr }}$ & $\boldsymbol{i}_{\text {corr }}$ & $\boldsymbol{\beta}_{\boldsymbol{a}}$ & $\boldsymbol{\beta}_{\boldsymbol{c}}$ & $\boldsymbol{R}_{\boldsymbol{p m}}, \boldsymbol{R}_{\boldsymbol{p}}$ \\
\cline { 2 - 6 } & $(\mathrm{V})$ & $\left(\mu \mathrm{A} \cdot \mathrm{cm}^{-2}\right)$ & $\left(\mathrm{V} \cdot \mathrm{decade}^{-1}\right)$ & $\left(\mathrm{V} \cdot \mathrm{decade}^{-1}\right)$ & $\left(\Omega \cdot \mathrm{cm}^{-2}\right)$ \\
\hline $\mathbf{R}$ & -0.36 & 1.79 & 0.08 & 0.15 & $1.24 \cdot 10^{4}$ \\
\hline A & -0.19 & 0.19 & 0.09 & 0.30 & $1.60 \cdot 10^{5}$ \\
\hline
\end{tabular}

Table 2. Penetration Rate, Protective Efficiency and Porosity Calculation Results from Potentiodynamic Polarization Data after $24 \mathrm{~h}$ Immersion

\begin{tabular}{|l|c|c|c|}
\hline \multirow{2}{*}{$\mathbf{R}$} & $\mathbf{C R}$ & $\mathbf{P}_{\mathbf{i}}$ & $\mathbf{F}$ \\
\cline { 2 - 4 } & $\left(\mathrm{mm} \cdot \mathrm{year}^{-1}\right)$ & $(\%)$ & $(\%)$ \\
\hline A & $3.75 \cdot 10^{-3}$ & - & - \\
\hline $\mathbf{B}$ & $8.43 \cdot 10^{-4}$ & 89.24 & 0.51 \\
\hline
\end{tabular}


The obtained Nyquist plots exhibit an overlay of at least two semicircles for all the samples, indicating multiple time constants due to a short exposure time in the simulated marine environment. It could be concluded that the applied short exposure duration (10 $\mathrm{min})$ is not sufficient to reveal the significant degradation of the substrate [30], [34], as shown in Fig. 5. The TiAlN coated material exposed for a short period exhibits the highest charge transfer resistance $\left(\mathrm{R}_{\mathrm{ct}}\right)$ as compared to TiCN coated sample exposed for a short period, as demonstrated in Table 3. The absolute impedance increases in the same order (AISI 316; TiCN, and TiAlN), as demonstrated in Fig. 6 a $(\log |Z|$ vs. $\log (f)-$ Bode plot). Phase angles of stainless steel and coated samples are about 67 and $77^{\circ}$, respectively, as demonstrated in Fig. 6 b (phase angle vs. $\log$ (f) - Bode plot). This result indicates a slightly more homogeneous surface of coated samples as compared to uncoated stainless steel. The inhomogeneous behaviour of stainless steel can be explained with the effect of the naturally formed oxide coating on the alloy surface which consists of different types of oxides with different resistance to degradation under simulated marine conditions.

The generated equivalent circuit for AISI 316 stainless steel substrate after long exposure $(24 \mathrm{~h})$ is demonstrated in Fig. 8. This circuit consists of double layer capacitance $\left(Q_{d l}\right)$ parallel to the charge transfer resistance $\left(R_{c t}\right)$. Both are in series with the solution resistance $\left(R_{s}\right)$ located between the working electrode (WE) and the tip of the Lugging capillary. The EQUIVCRT software is programmed to regard the $Q$ for the constant phase element. This element accounts for deviations from ideal dielectric behaviour related to the surface inhomogeneities, calculated according to Eq. (6):

$Y(\omega)=Y_{0}(j \cdot \omega)^{n_{d l}}$, where $Y_{0}$ is the adjustable parameter applied to non-linear least squares fitting; $n_{d l}$ is an adjustable parameter in the range from 0.5 up to 1 and is generated from the slope of $\log |\mathrm{Z}|$ vs. $\log$ (f) (Bode plot). The phase angle $\boldsymbol{\theta}$ varies between $0^{\circ}\left(n_{d l}=0\right.$ in the case of a perfect resistor) and $90^{\circ}\left(n_{d l}=1\right.$ in the case of a perfect capacitor). A value of $\boldsymbol{\theta}$ between 60 and $70^{\circ}$ represents a leaky capacitor behaviour of stainless steel with $\left.n_{d l}=0.78\right)$. TiCN and TiAlN exposed for a short period exhibit perfect resistor and capacitor behaviour, respectively. These effects can be explained with high passivity of the TiCN coatings to the saline water and low wettability caused by the presence of carbon [35], which also limits the penetration of the water into pores of the coating. However, the presence of aluminium in the TiAlN coating leads to a hydrolyzation reaction between free Al and water. Corrosion products like amorphous aluminium monohydroxide $\left(\mathrm{AlOOH}_{\text {amorph }}\right)$ and crystalline aluminium hydroxide $\left(\mathrm{Al}(\mathrm{OH})_{3 \text { crystal }}\right)$ form and generate the highly passivating layer on the surface of the TiAlN coating [36].

This effect leads to replacement of double layer capacitance $\left(C_{d l}\right)$ by the constant phase element at $n_{d l}<1$. The circuit description code (CDC) for the AISI 316 stainless steel after $24 \mathrm{~h}$ long exposure to aqueous 3.5 wt. $\% \mathrm{NaCl}$ solution matches the $R[Q R]$, as demonstrated in Fig. 8 .

The low coating thickness typically leads to rapid formation of localized galvanic cells (galvanic corrosion occurs) due to penetration of aqueous solution (electrolyte) into pores almost immediately after the immersion of coated material [37] of the equivalent circuits for electrochemical impedance spectroscopy (EIS). Therefore, corrosion occurs at two interfaces consisting of electrolyte coating and electrolyte substrate. The presence of an adhesive 
interlayer and the use of gradient or multilayer PVD coatings typically cause additional galvanic corrosion sub-interfaces between layers with different electrochemical properties (potentials).

Previous exposure of specimen to the air leads to a slight reduction in a corrosion rate caused by the decreased aqueous solution penetration rate through the defects of coatings even after bubbling of cell with nitrogen gas. The finite length diffusion process requires the adoption of the cotangent diffusion element $(O)$ in series with the charge transfer resistance in CDC of tested PVD TiCN and TiAlN coatings. The resulting $\mathrm{CDC}$ can be expressed as $R(Q[R(Q[R O])])$ to fit the electrochemical impedance spectroscopy data of the coated samples after $24 \mathrm{~h}$ immersion in the simulated marine conditions, as demonstrated in Fig. 9. The cotangent diffusion element is typically applied for simulation of finite length diffusion in the case of one boundary imposing a fixed concentration for diffusing species [38]; therefore, the complex admittance of finite length diffusion can be expressed according to Eq. (7).

$$
Y(\omega)=\left\{Y_{0}(j \cdot \omega)^{1 / 2}\right\} \operatorname{coth}\left[B Y_{0}(j \cdot \omega)^{1 / 2}\right] .
$$

The equation includes two parameters an admittance $\left(Y_{0}\right)$ and a time constant $(B)$. Reactant diffusion duration through the coating is characterised by the "time constant" parameter, which can be expressed according to Eq. (8).

$B=\frac{\delta}{\sqrt{D}}$,

where $D$ is the diffusion coefficient and $\delta$ is the thickness of the coating.

The coating capacitance $\left(Q_{\text {coat }}\right)$ value after $24 \mathrm{~h}$ exposure is the highest for TiCN (94), indicating a more homogeneous surface as compared to TiAlN coated specimen. The inhomogeneity of TiAlN coating contributes not only to the surface roughness and defects in the coating, but also to the presence of reactive $\mathrm{Al}$ and coating generated by the reaction products (e.g., $\mathrm{AlOOH}$ ) [18]. The aqueous $3.5 \mathrm{wt} . \% \mathrm{NaCl}$ solution penetrates trough all defects of the original coating and reaction products by accessing the unreacted material.

The presence of micrometre sized pores in the tested coatings results in the decreased coating capacitance and the increased charge transfer resistance after $24 \mathrm{~h}$ long exposure. The long exposure results in insignificant variations in the $Q_{d l}$ and $n_{d l}$ values of the tested coatings as compared to the stainless steel substrate. The shape of Bode plots after long exposure indicates the same corrosion mechanisms occurring in TiCN and TiAlN coatings.

Table 3. EIS Data Obtained by Equivalent Circuit to Fit Tested

Coatings Studied after $10 \mathrm{~min}$ and $24 \mathrm{~h}$ Immersion

\begin{tabular}{|l|c|c|c|c|c|c|c|c|c|}
\hline Tested specimen & $\begin{array}{c}R_{s} \\
\left(\Omega \cdot \mathrm{cm}^{2}\right)\end{array}$ & $\begin{array}{c}C_{\text {coat }}-Y_{0} \\
\left(\mu \mathrm{F} \cdot \mathrm{cm}^{-2}\right)\end{array}$ & $n_{\text {coat }}$ & $\begin{array}{c}R_{\text {pore }} \\
\left(\Omega \cdot \mathrm{cm}^{2}\right)\end{array}$ & $\begin{array}{c}Q_{d l}-Y_{0} \\
\left(\mu \mathrm{F} \cdot \mathrm{cm}^{-2}\right)\end{array}$ & $n_{d l}$ & $\begin{array}{c}R_{c t} \\
\left(\mathrm{k} \Omega \cdot \mathrm{cm}^{2}\right)\end{array}$ & $\begin{array}{c}O-Y_{0} \\
\left(\mu \Omega \cdot \mathrm{cm}^{2} \cdot \sqrt{s}\right)\end{array}$ & $\begin{array}{c}B \\
(\sqrt{s})\end{array}$ \\
\hline R (AISI 316) & 18.1 & - & - & - & 83.1 & 0.78 & 82 & - & - \\
\hline R (AISI 316) & 18.5 & - & - & - & 0.16 & 0.90 & 1.62 & - & - \\
\hline $\mathbf{A}(\mathbf{T i C N})_{\mathbf{1 0} \text { min }}$ & 19.5 & 6.36 & 0.84 & 3.22 & $900 \cdot 10^{-13}$ & 0 & 2.47 & 18.1 & $6.47 \cdot 10^{-6}$ \\
\hline $\mathbf{A}(\mathbf{T i C N})_{\mathbf{2 4 h}}$ & 18.4 & 94.0 & 0.72 & 180 & 0.10 & 0.76 & 2.17 & 2704 & 1.51 \\
\hline B (TiAIN) $\mathbf{1 0}_{\min }$ & 20.1 & 37.0 & 0.85 & 0.21 & 9.88 & 1.00 & 14.3 & 19.7 & 1.52 \\
\hline B (TiAIN) & 19.4 & 91.1 & 0.85 & 390 & 0.16 & 0.96 & 3.51 & 12700 & 8.74 \\
\hline
\end{tabular}




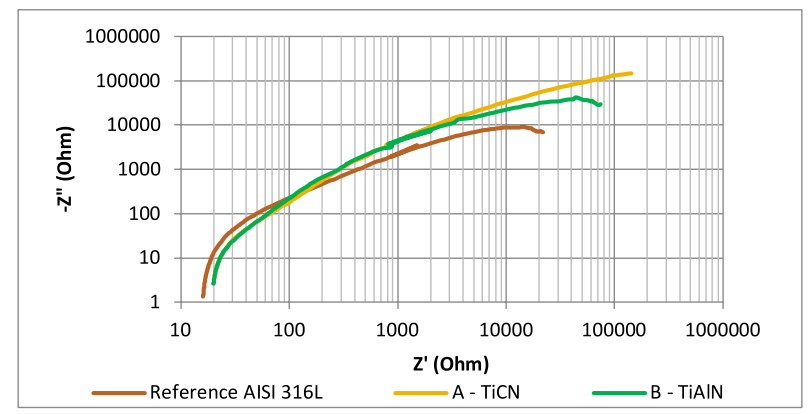

Fig. 5. Nyquist plots of the tested specimens after $10 \mathrm{~min}$ immersion.

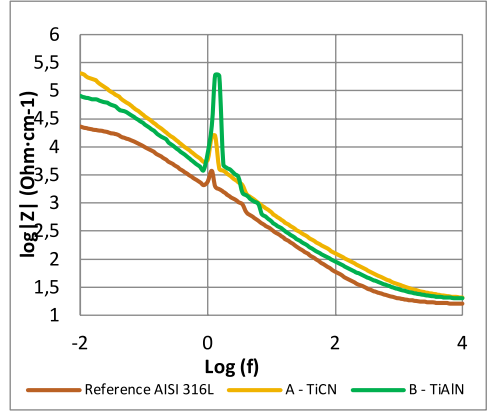

a

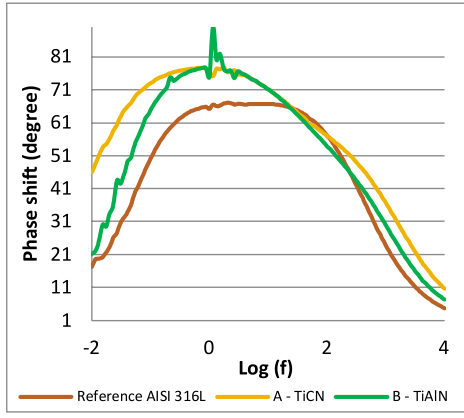

$\mathrm{b}$

Fig. 6. Bode plots of the tested specimens after $10 \mathrm{~min}$ immersion: (b) $-\log |Z|$ vs. $\log$ (f); (a) - phase angle vs. $\log$ (f).

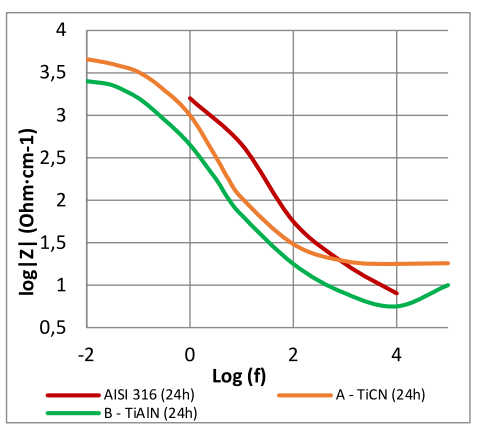

a

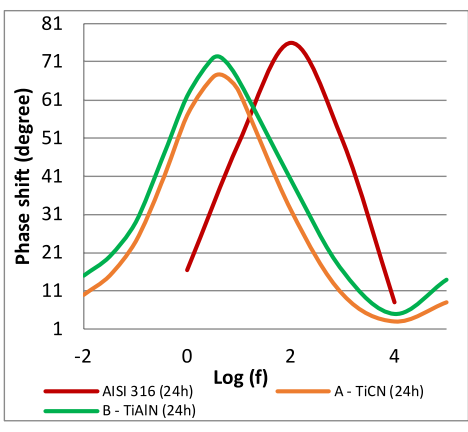

b

Fig. 7. Bode plots of the tested specimens after $24 \mathrm{~h}$ immersion: (b) $-\log |\mathrm{Z}|$ vs. $\log (\mathrm{f})$; (a) - phase angle vs. $\log (\mathrm{f})$.

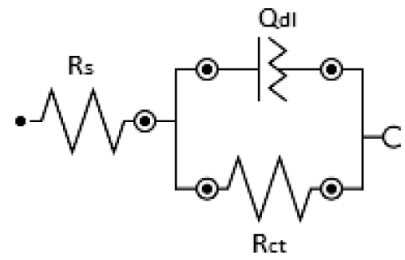

Fig. 8. Equivalent circuit to fit the electrochemical impedance spectroscopy data of the AISI 316 after 10 min immersion. 


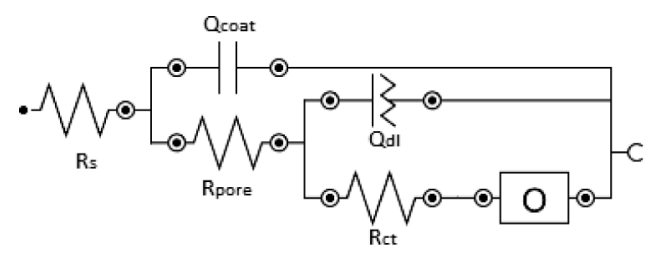

Fig. 9. Equivalent circuit to fit the electrochemical impedance spectroscopy data of the coated samples after $24 \mathrm{~h}$ immersion.

\section{CONCLUSIONS}

The thickness of the produced TiCN and TiAlN coatings from 2 up to $3.5 \mu \mathrm{m}$ provides up to $95 \%$ higher protective efficiency as compared to the surface of the mesh shaped stainless steel AISI 316 substrate (reference sample) after $10 \mathrm{~min}$ immersion and $24 \mathrm{~h}$ exposure under simulated marine conditions (3.5 wt. \% NaCl solution). The selected PVD coating method leads to the formation of low porosity (up to $0.51 \%$ in the case of $\mathrm{TiCN}$ ). The presence of free $\mathrm{Al}$ in TiAlN coating leads to the formation of passive $\mathrm{AlOOH}$ reaction product.

The increased duration of immersion up to $24 \mathrm{~h}$ leads to penetration of liquid inside the pinholes and macrodefects with diameters less than $10 \mu \mathrm{m}$. This process results in $E_{\text {corr }}$ shifting toward a more negative potential as compared to samples after immersion for a short period of time. It can be concluded that TiAlN PVD gradient coating can provide higher protection efficiency after short immersion time, while TiCN PVD gradient coating can maintain less changed protective efficiency after $24 \mathrm{~h}$ long immersion under the simulated marine conditions (3.5 wt. \% NaCl solution).

The EIS measurements indicate that TiAlN coating exhibits better corrosion resistance after $24 \mathrm{~h}$ exposure to the simulated marine condition due to the formation of $\mathrm{AlOOH}$ as compared to the tested $\mathrm{TiCN}$ coated and uncoated mesh shaped stainless steel 316.

\section{ACKNOWLEDGEMENTS}

The research has been supported by the by the Ministry of Education and Science of Latvia within postdoctoral research project No. 1.1.1.2/VIAA/3/19/477. The authors thank the teams of Riga Technical University (Latvia), Klaipeda University (Lithu- ania), and Tallinn University of Technology (Estonia) for support in providing the failed screen filter, production of specimens, and electrochemical performance tests, respectively. 


\section{REFERENCES}

1. Irtiseva, K., Baronins, J., Krūmiņšs, J., Ozolins, J., Kḷaviņš, M., \& Medne, O. (2020). Development of Peat Processing Methods for Production of Innovative Products. Key Eng. Mater., 850, 9-15.

2. Kommel, L., \& Baronins, J. (2017). Dependence of Wear of Cu-Cr-S Alloy on Hardness and Electrical Conductivity in Sliding Electrical Contact. Solid State Phenomena, 267, 229-233.

3. Arshad, A., Samarasinghe, S., Akeel, F.A.M., \& Urbahs, A. (2020). A Simplified Design Approach for High-Speed Wind Tunnels. Part I: Table of Inclination. $J$. Mech. Sci. Technol., 34, 2455-2468.

4. Arshad, A., Andrew, N., \& Blumbergs, I. (2020). Computational Study of noise reduction in CFM56-5B using core nozzle chevrons. In: Proceedings of the 11th International Conference on Mechanical and Aerospace Engineering (ICMAE) (pp. 162-167), IEEE, 2020.

5. Kalnina, R., \& Romule, A. (2020). Analysis of Ballast Water Treatment Technologies on Ships Operating in the Baltic Sea Region. Transp. Aerosp. Eng., 8, 15-20.

6. Shishkin, A., Mironovs, V., Vu, H., Novak, P., Baronins, J., Polyakov, A., \& Ozolins, J. Cavitation-Dispersion Method for Copper Cementation from Wastewater by Iron Powder. Metals (Basel), 8, 920.

7. WWF International. (2009). Silent invasionThe spread of marine invasive species via ships'ballast water. Gland, Switzerland.

8. Drake, L.A., Wier, T.P., Parson, E.W.J., \& Grant, J.F. (2016). Recommendations for evaluating multiple filters in ballast water management systems for US type approval. USA: Naval Research Laboratory.

9. ALfa Laval Corporate AB. (2017). Muddy waters and filter clogging in ballast water treatment. Tigre, Argentina. Available at https://www.alfalaval.lat/globalassets/ documents/products/process-solutions/ ballast-water-solutions/muddy_waters and_filter_clogging_in_ballast_water_- treatment.pdf

10. Andersen, A.B. (2017). Should you Accept Stainless Steel Filter-Screens in your Ballast Water Management System? Available at https://www.linkedin.com/pulse/shouldyou-accept-stainless-steel-filter-screensyour-andersen/

11. Bhushan, B., \& Gupta, B.K. (1991). Handbook of tribology: Materials, coatings, and surface treatments. USA: McGrawHill.

12. Cai, F. (2011). Tribological and electrochemical corrosion behaviours of titanium nitride and chromium nitride based PVD coating systems. PhD Thesis. Princeton: Princeton University. ISBN 9780494815458.

13. Sharifinia, M., Bahmanbeigloo, Z.A., Keshavarzifard, M., Khanjani, M.H., \& Lyons, B.P. (2020). Microplastic Pollution as a Grand Challenge in Marine Research: A Closer Look at their Adverse Impacts on the Immune and Reproductive Systems. Ecotoxicol. Environ. Saf., 204, 111109.

14. Transparency Market Research. (n.d.). High-Performance Anti-Corrosion Coatings Market. Available at https:// www.transparencymarketresearch.com/ high-performance-anticorrosion-coatingsmarket.html

15. Méndez, C.M., Covinich, M.M., \& Ares, A.E. (2013). Resistance to corrosion and passivity of $316 \mathrm{~L}$ stainless steel directionally solidified samples. In M. Aliofkhazraei (Ed.), Developments in Corrosion Protection (pp. 41-63). ISBN 978-953-51-1223-5.

16. Baronins, J., Podgursky, V., Antonov, M., Bereznev, S., \& Hussainova, I. (2016). Electrochemical Behaviour of $\mathrm{TiCN}$ and TiAlN Gradient Coatings Prepared by Lateral Rotating Cathode Arc PVD Technology. Key Eng. Mater., 721, 414-418.

17. Panjan, P., Čekada, M., Panjan, M., \& KekMerl, D. (2009). Growth Defects in PVD Hard Coatings. Vacuum, 84, 209-214. 
18. Baronins, J., Antonov, M., Bereznev, S., Raadik, T., \& Hussainova, I. (2018). Raman Spectroscopy for Reliability Assessment of Multilayered AlCrN Coating in TriboCorrosive Conditions. Coatings, 8 (7), 229.

19. Shishkin, A., Kozlov, V., Drozdova, M., Rulev, J., Mironov, V., \& Hussainova, I. (2016). Low-density composite powder for lightweight parts made by means powder metallurgy. In Proceedings of the World PM2016; European Powder Metallurgy Association (EPMA) (pp. 93-94). 9-13 October 2016, Hamburg, Germany.

20. Shishkin, A., Drozdova, M., Kozlov, V., Hussainova, I., \& Lehmhus, D. (2017). Vibration-Assisted Sputter Coating of Cenospheres: A New Approach for Realizing Cu-Based Metal Matrix Syntactic Foams. Metals (Basel), 7, 16.

21. Shishkin, A., Hussainova, I., Kozlov, V., Lisnanskis, M., Leroy, P., \& Lehmhus, D. (2018). Metal-Coated Cenospheres Obtained via Magnetron Sputter Coating: A New Precursor for Syntactic Foams. JOM, 70 (7), 1319-1325.

22. Hoche, H., Groß, S., \& Oechsner, M. (2014). Development of New PVD Coatings for Magnesium Alloys with Improved Corrosion Properties. Surf. Coatings Technol., 259, 102-108.

23. Taha, M.A., El-Mahallawy, N.A., Hammouda, R.M., \& Nassef, S.I. (2010). PVD Coating of Mg-AZ31 by Thin Layer of Al and Al-Si. J. Coatings Technol. Res., 7, 793-800.

24. Wang, C.,Wang, G., Feng, Z., Ji, X., Li, Q., Zhang, Z., \& Song, D. (2011). Strengthen Water Conservancy Construction, Use Water Resources Scientifically, and Develop Modern Agriculture. Procedia Environ. Sci., 10, 1595-1600.

25. Williams, J. A. (1999). Wear Modelling: Analytical, Computational And Mapping: A Continuum Mechanics Approach. Wear, 225-229, 1-17.

26. Merl, D.K., Panjan, P., Panjan, M., \& Čekada, M. (2007). The Role of Surface Defects Density on Corrosion Resistance of PVD Hard Coatings. Plasma Process. Polym., 4, 613-617.
27. Yang, M., Allen, A.J., Nguyen, M.T., Ralston, W.T., MacLeod, M.J., \& DiSalvo, F.J. (2013). Corrosion Behavior of Mesoporous Transition Metal Nitrides. J. Solid State Chem., 205, 49-56.

28. Ibrahim, M.A.M., Korablov, S.F., \& Yoshimura, M. (2002). Corrosion of Stainless Steel Coated with TiN, (TiAl)N and $\mathrm{CrN}$ in Aqueous Environments. Corros. Sci., 44, 815-828.

29. Baronins, J., Antonov, M., Bereznev, S., Raadik, T., \& Hussainova, I. (2019). Raman Spectroscopy of Multilayered $\mathrm{AlCrN}$ Coating under High Temperature Sliding/ Oxidation. Key Eng. Mater., 799, 9-14.

30. William Grips, V.K., Barshilia, H.C., Selvi, V.E., \& Rajam, K.S. (2006). Electrochemical Behavior of Single Layer CrN, TiN, TiAlN Coatings and Nanolayered TiAlN/CrN Multilayer Coatings Prepared by Reactive Direct Current Magnetron Sputtering. Thin Solid Films, 514, 204-211.

31. Urbahs, A., Savkovs, K., Urbaha, M., \& Kurjanovičs, I. (2012). Nanostructured Intermetal-Ceramic Coatings for Blades of Gas Turbine Engines. Nanodevices and Nanomaterials for Ecological Security: NATO Science for Peace and Security Series B: Physics and Biophysics, 307-314. Dordrecht: Springer.

32. ASTM. (1997). ASTM G59 - 97e1 Standard Test Method for Conducting Potentiodynamic Polarization Resistance Measurements. ASTM International: West Conshohocken.

33. Yoo, Y.H., Le, D.P., Kim, J.G., Kim, S.K., \& Van Vinh, P. (2008). Corrosion Behavior of TiN, TiAlN, TiAlSiN Thin Films Deposited on Tool Steel in the $3.5 \mathrm{wt} . \% \mathrm{NaCl}$ Solution. Thin Solid Films, 516, 3544-3548.

34. Liu, H.-N., Nomura, M., Ogi, K., \& Sakamoto, M. (2001). Abrasion Resistance of High Cr Cast Irons at an Elevated Temperature. Wear, 250, 71-75.

35. Subramanian, B., Thampi,A., Manivasagam, G., \& Dhandapani, P. (2015). Influence of Needle-Like Morphology on the Bioactivity of Nanocrystalline Wollastonite - An in Vitro Study. Int. J. Nanomedicine, 107-118. 
36. Bowen, P., Highfield, J.G., Mocellin, A., \& Ring, T.A. (1990). Degradation of Aluminum Nitride Powder in an Aqueous Environmet. J. Am. Ceram. Soc., 73, 724728.

37. Liu, C., Bi, Q., Leyland, A., \& Matthews, A. (2003). An Electrochemical Impedance Spectroscopy Study of the Corrosion Behavior of PVD Coated Steels in 0.5 $\mathrm{N} \mathrm{NaCl}$ Aqueous Solution: Part II. EIS Interpretation of Corrossion Behaviour. Corros. Sci., 45, 1257-1273.
38. BOUKAMP, B. A (1986). Nonlinear Least Squares Fit Procedure for Analysis of Immittance Data of Electrochemical Systems. Solid State Ionics, 20, 31-44. 